\title{
CORRIGENDUM
}

\section{The estimated disease burden of norovirus in The Netherlands - CORRIGENDUM}

\author{
L. VERHOEF, M. KOOPMANS, W. VAN PELT, E. DUIZER, J. HAAGSMA, \\ D. WERBER, L. VAN ASTEN AND A. HAVELAAR.
}

doi: 10.1017/S0950268812000799, Published by Cambridge University Press, 17 May 2012.

An incorrect value for disability-adjusted life-years in a population of 16.5 million was given in the summary on page 1 of the paper by L. Verhoef, M. Koopmans, W. van Pelt, E. Duizer, J. Haagsma, D. Werber, L. van Asten and A. Havelaar.[1]. The corrected sentence is published below:

The general population incidence was 3800/100000 (95\% CI 2670-5460), including $0 \cdot 4$ fatal cases/100 000, resulting in 1622 (95\% CI 966-2650) disability-adjusted life-years in a population of 16.5 million.

\section{REFERENCE}

1. L. Verhoef, M. Koopmans, W. van Pelt, E. Duizer, J. Haagsma, D. Werber, L. van Asten and A. Havelaar The estimated disease burden of norovirus in The Netherlands. Epidemiology and Infection. Published by Cambridge University Press, 17 May 2012. doi: 10.1017/S0950268812000799 